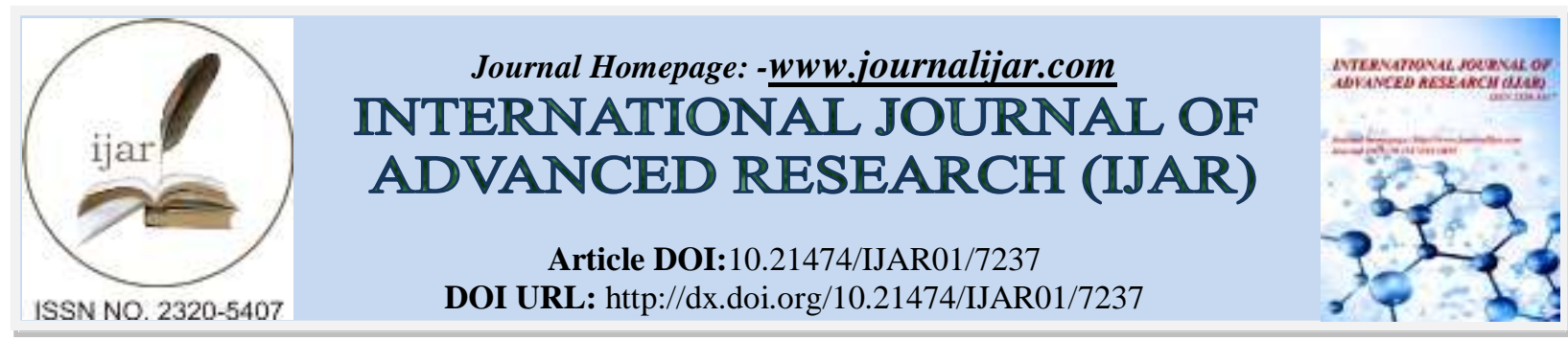

RESEARCH ARTICLE

\title{
EVALUATION OF COAGULATION PROFILE IN PATIENTS WITH PREGNANCY INDUCED HYPERTENSION IN PATIENTS ATTENDING A TERTIARY CARE HOSPITAL IN NORTH INDIA.
}

Farhat Ali Lone ${ }^{1}$, Sabha Malik ${ }^{1}$, Shaheera Ajaz ${ }^{1}$, Liaqat Ahmad Malik ${ }^{2}$ And Parvaiz Mohiudin Dar ${ }^{2}$.

1. Department of Obstetrics and Gynaecology, Sher-e-Kashmir Institute of Medical Sciences (SKIMS), Soura $\mathrm{J} \& \mathrm{~K}$.

2. Department of General and minimal access Surgery, ,Sher-e-Kashmir Institute of Medical Sciences(SKIMS), Soura J\&K.

\section{Manuscript Info}

(...........................

Manuscript History

Received: 09 April 2018

Final Accepted: 11 May 2018

Published: June 2018

\section{Abstract}

Pregnancy induced hypertension (PIH) is one of the most common causes of both maternal and neonatal morbidity and associated with adverse pregnancy outcomes.Profound changes in coagulation and fibrinolytic system occur during normal pregnancy causing hypercoagulable state. Early identification of high risk women and monitoring derangements in their coagulation system are surely pivotal in the prevention of complications. Hence, this study was undertaken to compare the coagulation profile in pre-eclamptic and eclamptic patients with normotensive pregnant patients Hypertension is one of the common medical complications of pregnancy and contributes significantly to maternal and perinatal morbidity and mortality. Hypertension is a sign of an underlying pathology which may be preexisting or appear for the first time during pregnancy. Various haematological changes like numerical and functional platelet abnormalities, alteration in haemoglobin and erythrocyte parameters and hypercoagulable state may be seen.

Aims and Objectives: Evaluation of coagulation profile in PIH.

Materials and Methods: A one year study was carried in the department of gynaecology and obstetrics on 100 PIH cases. Coagulation profile (PT, aPTT, INR and D-dimer) was done in all cases and values were correlated with the severity of PIH.

Results: Total of 100 cases were included in the study. 32 were mild $\mathrm{GH}, 17$ cases were severe $\mathrm{GH}, 35$ cases were mild pre-eclampsia and 16 cases were in severe pre-eclampsia group. Prolonged PT, aPTT and D-Dimer was seen in 15 cases, 42 cases and 38 cases respectively. In our study we observed increased mean aPTT of $31.61+-2.89$ and increased D-Dimer of $0.34 \pm 0.31$ in severe pre-eclampsia patients. Hence we emphasize that raised aPTT, D-Dimer are alarming signs for aggressive treatment.

Conclusion: Raised aPTT and D-dimer are fairly good indicator of severe pre-eclampsia and needs aggressive treatment.

Copy Right, IJAR, 2018,. All rights reserved. 


\section{Introduction:-}

Hypertensive disorders complicates 5 to $10 \%$ of all pregnancies ,contribute significant to perinatal and maternal mortality and morbidity. According to systematic review by WHO hypertensive disorders account for $16 \%$ of maternal deaths in developed countries ${ }^{1}$. Hypertensive disorders in pregnancy is one of the commonest medical disorders in pregnancy diagnosed by obstetricians in clinical practice and is one of the major causes of maternal \& perinatal morbidity and mortality ${ }^{2}$. Approximately $1,00,000$ women die worldwide per annum because of eclampsia ${ }^{2}$ .It is said that preeclampsia and eclampsia contribute to death of a woman every 3 minute worldwide ${ }^{3}$ Preeclampsia is a common dangerous condition for both mother and baby and is also predictable in onset and progression.

Hypertension is one of the most common medical complications of pregnancy. It contributes significantly to maternal and perinatal morbidity and mortality. Hypertension is a sign of an underlying pathology which may be pre-existing or appear for the first time during pregnancy ${ }^{4}$. Hypertension affects $7-15 \%$ of all pregnancies. It is associated with $16 \%$ of all maternal mortality and $20 \%$ of all perinatal mortality in India ${ }^{4,5}$.

Pregnancy induced hypertention (PIH) is defined as hypertension that develops as the direct result of the gravid state. It includes, i) Gestational hypertension, ii) Preeclampsia, iii) Eclampsia.

Hematological abnormalities such as thrombocytopenia and decrease in some plasma clotting factors may develop in preeclamptic women ${ }^{6}$.

In pregnancies with preeclampsia coagulation cascade is generally activated. Preeclampsia is a highly thrombotic and pro-coagulant state with platelet activation and thrombin and fibrin formation. About $20 \%$ of patients have altered coagulation ${ }^{7}$. Profound changes in coagulation and fibrinolytic system occur during normal pregnancy causing hypercoagulable state. The prothrombotic state may culminate in a process of chronic disseminated intravascular coagulation (DIC) leading to changes in kidney and placenta ${ }^{8}$. These underlying coagulation abnormalities increase the risk of bleeding complications especially during operative deliveries. These subtle changes consistent with DIC occurring in pre-eclampsia and are potentially serious ${ }^{9}$.In the mother, pre-eclampsia may cause premature cardiovascular diseases, such as chronic hypertension, heart disease and stroke. Later in life, while children born after pre-eclamptic pregnancies and who are relatively small at birth, have an increased risk of stroke, coronary heart disease and metabolic syndrome in adult life ${ }^{10}$. Thus, early identification of such high risk women and monitoring derangements in their coagulation system are surely pivotal in the prevention of complications.Hence, this study was undertaken to compare the coagulation profile in pre-eclamptic and eclamptic patients with normotensive pregnant patients.

\section{Aims And Objectives:}

Evaluation of coagulation profile in PIH patients.

\section{Materials And Methods:}

The study was carried out in the department of gynaecology and obstetrics SKIMS srinagar. One hundred cases diagnosed as PIH with Blood Pressure of $\geq 140 / 90 \mathrm{~mm}$ of $\mathrm{Hg}$ detected after 20th weeks of gestation were included in the study. Clinical details were collected from all cases. The cases with pre-existing hypertension and associated co-morbid diseases such as diabetes mellitus, auto immune disorders, ITP, neoplastic diseases, heart diseases and cases on anti-coagulants were excluded from the study. After obtaining consent, under aseptic precaution, venous blood was collected in sodium citrate vacutainer tube. Sample was tested for coagulation profile i.e. PT, aPTT, DDimer in fully automated coagulation analyser (CA-1500). PIH cases were classified in to following categories:

A.Gestational hypertension.1) Mild gestational hypertension, 2) Severe gestational hypertension.

B. Pre-eclampsia. 1) Mild pre-eclampsia, 2) Severe pre-eclampsia.

\section{Statistical Methods:}

The recorded data was compiled and entered in a spreadsheet (Microsoft Excel) and then exported to data editor of SPSS Version 20.0 (SPSS Inc., Chicago, Illinois, USA). Continuous variables were expressed as Mean \pm SD and categorical variables were summarized as frequencies and percentages. Graphically the data was presented by bar diagrams. Analysis of variance (ANOVA) was employed to compare coagulation profile in different categories of PIH. A P-value of less than 0.05 was considered statistically significant. 


\section{Results:-}

One hundred cases diagnosed as PIH were analysed for coagulation profile. Of 100 cases majority i.e. $36 \%$ of the patients were of the age group 25-30 years. (Table. 1) The age of the youngest patient was 20 years and that of oldest was 40 years. 25to 30 years is the commonest age group for gestational hypertension (GH), both mild (15cases) and severe (7cases). An equal number of severe GH was also seen in the 26 to 30 age group. Mild and severe pre-eclampsia was more frequent in the 26 to 30 age group, (16 and 8 cases respectively). This probably indicates that severity of complications increases with the age of the patient. (Table. 2) of the hundred PIH cases.

Table 1: Demographic characteristics

Table 1: Age distribution of study patients

\begin{tabular}{|l|l|l|}
\hline Age (years) & Frequency & Percentage \\
\hline $20-25$ & 17 & $17 \%$ \\
\hline $25-30$ & 36 & $36 \%$ \\
\hline $30-35$ & 31 & $31 \%$ \\
\hline $35-40$ & 16 & $16 \%$ \\
\hline Total & 100 & $100 \%$ \\
\hline
\end{tabular}

Total number of patients in this study were 100 with maximum number of patients in age group of 25 to 30 years followed by patients in age group of 30 to 35 years. This result showed that PIH increases with increasing age among women( $67 \%$ in age 25 and above).

Table 2:-Table showing age wise distribution of various categories of PIH cases

\begin{tabular}{|l|l|l|l|l|l|l|l|l|}
\hline \multicolumn{2}{|l|}{$\begin{array}{l}\text { Age } \\
\text { (years) }\end{array}$} & Mild GH & \multicolumn{1}{l|}{ Severve GH } & \multicolumn{2}{l|}{ Mild Preeclampsia } & \multicolumn{2}{l|}{ Severe PRE Eclampsia } \\
\cline { 2 - 9 } & No. & \%age & No. & \%age & No. & \%age & No. & \%age \\
\hline $20-25$ & 3 & 9.4 & 3 & 17.6 & 7 & 20.0 & 2 & 12.5 \\
\hline $25-30$ & 15 & 46.9 & 6 & 35.3 & 16 & 45.7 & 8 & 50.0 \\
\hline $30-35$ & 11 & 34.4 & 7 & 41.2 & 10 & 28.6 & 4 & 25.0 \\
\hline $35-40$ & 3 & 9.4 & 1 & 5.9 & 2 & 5.7 & 2 & 12.5 \\
\hline Total & 32 & 100 & 17 & 100 & 35 & 100 & 16 & 100 \\
\hline
\end{tabular}

This table is showing that among 100 patients mild gestational hypertension (46.9\%) was in age group of 25 to 30 years; severe gestational hypertension (34.4\%) in 30 to 35 years age group; mild pre-eclampsia (45.7\%) in 25 to 30 years age group and severe pre-eclampsia (50\%) in age gourp in 25 to 30 years.

Table 3:-Table showing $\mathrm{d} D$ dimers in various categories of PIH cases

\begin{tabular}{|l|l|l|l|l|l|l|l|l|}
\hline \hline \multirow{2}{*}{ D Dimer } & \multicolumn{2}{l}{ Mild GH } & \multicolumn{2}{l|}{ Severe GH } & \multicolumn{2}{l|}{ Mild Preeclampsia } & \multicolumn{2}{l|}{ Severe Eclampsia } \\
\cline { 2 - 9 } & No. & \%age & No. & \%age & No. & \%age & No. & \%age \\
\hline$<0.3$ & 19 & 59.4 & 8 & 47.1 & 25 & 71.4 & 10 & 62.5 \\
\hline $0.3-1$ & 13 & 40.6 & 9 & 52.9 & 10 & 28.6 & 6 & 37.5 \\
\hline Total & 32 & 100 & 17 & 100 & 35 & 100 & 16 & 100 \\
\hline
\end{tabular}

Table 4:-Comparison of coagulation profile in different categories of PIH

\begin{tabular}{|l|l|l|l|l|l|}
\hline \hline Variable & Mild GH & Severe GH & Mild Preeclampsia & Severe Preeclampsia & P-value \\
\hline Age (years) & $25.8 \pm 2.41$ & $26.3 \pm 3.19$ & $25.4 \pm 2.87$ & $25.7 \pm 3.24$ & 0.997 \\
\hline Gestational age (weeks) & $36.2 \pm 3.65$ & $35.3 \pm 3.19$ & $36.7 \pm 2.72$ & $35.5 \pm 3.41$ & 0.991 \\
\hline PT & $12.43 \pm 1.93$ & $13.41 \pm 1.32$ & $13.09 \pm 2.05$ & $12.97 \pm 1.97$ & 0.989 \\
\hline APTT & $25.92 \pm 3.07$ & $26.67 \pm 2.71$ & $28.82 \pm 3.23$ & $31.61 \pm 2.89$ & 0.685 \\
\hline D Dimer & $0.29 \pm 0.46$ & $0.32 \pm 0.27$ & $0.26 \pm 0.29$ & $0.34 \pm 0.31$ & 0.876 \\
\hline
\end{tabular}

This table shows value of aPTT increases with severity of PIH with maximum value in severe preeclampsia (31.61 \pm 2.89 ); also D dimers were in in higher range in severe preeclampsia as compared to others. So APTT and Ddimer can predict the severity of PIH and helps us to plan and manage patient accordingly to decrease maternal and fetal morbidity and mortality. 

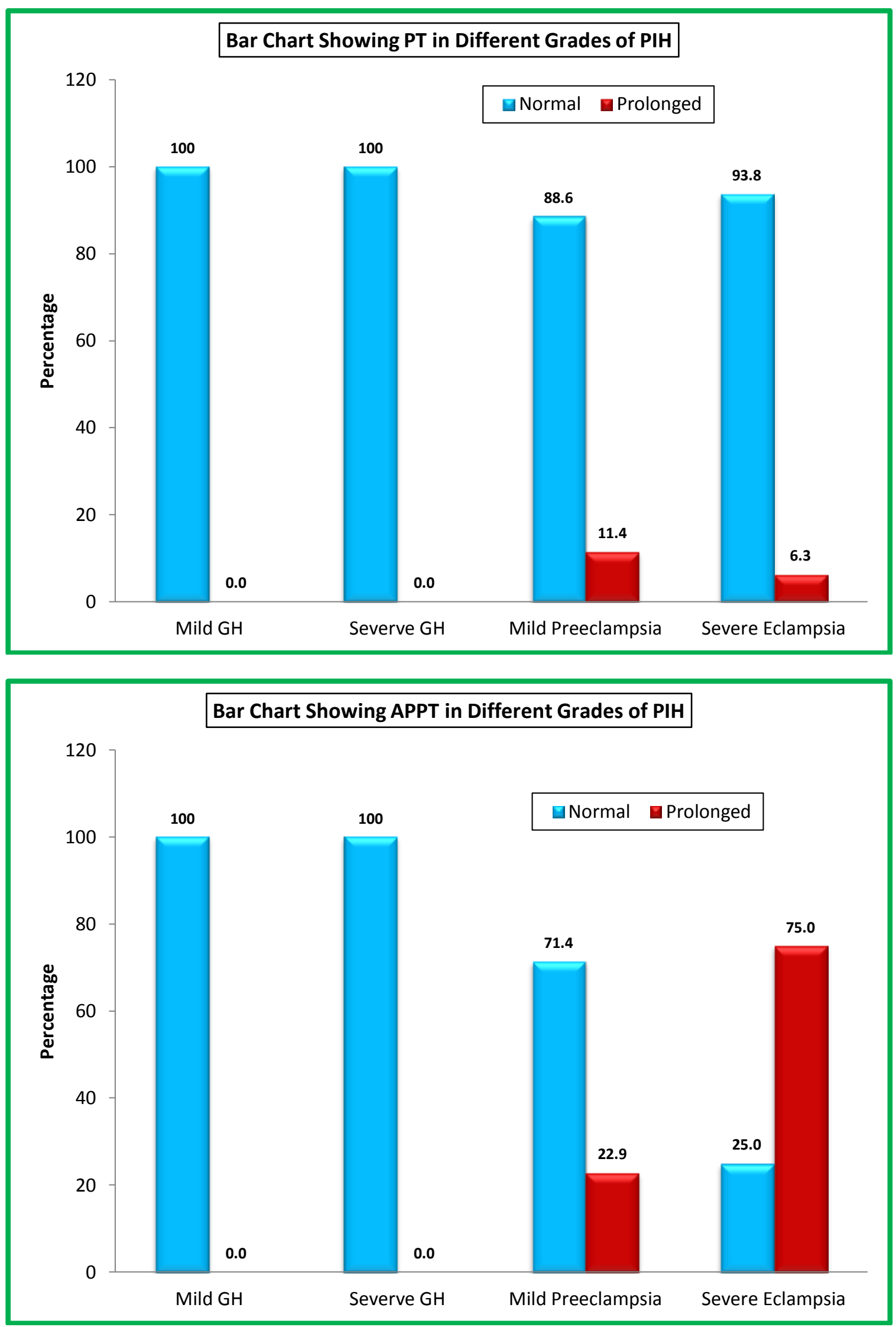


\section{Discussion:}

Preeclampsia is an idiopathic multisystem disorder specific to human pregnancy and the puerperium ${ }^{5}$.Hematological abnormalities such as thrombocytopenia and decrease in some plasma clotting factors may develop in preeclamptic women $^{2}$. Subtle changes suggesting disseminated intravascular coagulation (DIC) is one of the serious outcome of preeclampsia. Thus, coagulation testing is to be done in these patients to rule out DIC ${ }^{6,7}$ and HELLP (hemolysis, enzyme elevation and low platelet) syndrome. From the historical point of view, earlier it was stated that only serial measurements of platelet count was adequate for intrapartum screening ${ }^{8}$. Later, combination of platelet count and aPTT $^{6}$ platelet count and liver function tests ${ }^{9}$, platelet count and lactatedehydrogenase ${ }^{7}$, platelet count and antithrombin ${ }^{10}$ were suggested for early detection and screening of the patients with peeclampsia. It was observed that abnormal PT, aPTT and fibrinogen levels with platelet counts of less than $100,000 / \mathrm{mm} 3$ were seen in preeclampsia. So the physician can safely follow the platelet counts of the patients with severe preeclampsia ${ }^{8}$ In our study a total of 100 PIH cases referred to the department of pathology from ANC clinic were evaluated for coagulation profile. Majority of the cases were in the age group of 26-30 years with mean of $28 \pm 3.02$, which is comparable to Onisai et al study where they observed that the mean age of PIH was 29.8 years ${ }^{4}$.In the present study PT was prolonged in $5 \%$ which is in concordance with the study conducted by FitzGerald et $\mathrm{al}^{16}$. aPTT was prolonged in $20 \%$ of PIH cases in our study as compared with other studies such as FitzGerald et al. wherein $25 \%$ of cases had a prolonged aPTT. However Onisai et al observed no change in PT and aPTT in their study ${ }^{4}$.In the present study D-Dimer levels increased in $38 \%$ of PIH cases which is in concordance with the study conducted by Takao et $\mathrm{al}^{17}$.

Prolonged PT,aPTT and D-Dimer was seen in 5 cases , 20 cases and 38 cases respectively in our study and increased mean aPTT of $31.61 \pm 2.89$ and increased D-Dimer of $0.34 \pm 0.31$ in severe preeclampsia patients was noted. Hence we emphasize that raised aPTT, D-Dimer are alarming signs for aggressive treatment.

\section{Conclusion:-}

The coagulation parameters, especially aPTT and D-dimer can be used to monitor the progression of gestational hypertention to preeclampsia. Raised aPTT and D-dimer are fairly good indicators of severe preeclampsia and needs aggressive treatment.

\section{Acknowledgements:-}

The authors acknowledges the support provided by the co authors and patients.

\section{Conflict of interest}

It is certified that there was not any conflict of interest.

\section{Competing Interests}

The authors declare that there were no competing interests. 


\section{References:-}

1. Khan ks'WojdylaD,Etal.WHO analysis of causes of maternal death;a systematic review.Lancet.2006;367;1066.

2. Shah M R. Hypertensive disorders in pregnancy. 1st edn published by Jaypee. 2007: 1-10 3. Cunningham F G, Leveno K J, Bloom S L, Hauth J C, Gilstrap III. L.C, Wenstrm K. D. Hypertensive disorders in pregnancy. Ch 37 In William Obstetrics. 21st edn published by McGraw Hill Company; 2002: 871-90.

3. Cunningham F.G, Kenneth J. Leveno, StevenL.Bloom, John C. Pregnancy induced hypertention. In: Kenneth J. Leveno, StevenL.Bloom editor. William Obstetrics, 23rd ed. New York:McGraw-Hill; 2010. p. 706-56.

4. Dutta D C. Pregnancy induced hypertention. In:Dutta DC editor. Textbook of Obstretrics including Perinatalogy and Contaception, 7th ed. Kolkata:New Central Book Agency(P)Ltd; 2011. p. 219-40.

5. Norwitz ER, Hsu CD, RepkeJT.Acute complications of preeclampsia.ClinObstetGynecol2002;45:308-29.

6. Onisai M, VladareanerAM, Bumbea H, Clorascu M, Pop C, AndreiC, et al. A study of haematological picture and of platelet function in preeclampsia-report of a series of cases. J of Clin Med 2009;4:326-7.

7. Weiner CP, Brandt J. Plasma antithrombin-III activity: An aid in the diagnosis of pre-eclampsia-eclampsia. Am J ObstetGynecol 1982; 142:275-81.

8. Jahromi BN, Rafiee SH. Coagulation factors in severe preeclampsia. IRCMJ 2009; 11(3):321-4. 8. FitzGerald MP, Floro C, Siegel J, Hernandez E. Laboratory findings in hypertensive disorders of pregnancy. J Nat Med Assoc 1996; 88(12):794-98.

9. Osmond C, Kajantie E, Forsén TJ, Eriksson JG, Barker DJ. Infant growth and stroke in adult life: The Helsinki Birth Cohort Study. Stroke 2007; 38(2):264-70

10. Norwitz ER, Hsu CD, RepkeJT.Acute complications of preeclampsia.ClinObstetGynecol2002;45:308-29.

11. Metz J, Cincotta R, Francis M, DeRosa L, Balloch A. Screening for consumptive coagulopathy in preeclampsia. Int J GynecolObstet 1994;46:3-9.

12. Barron WM, Heckerling P, Hibbard JU, Fisher S. Reducing unnecessary coagulation testing in hypertensive disorders of pregnancy. ObstetGy-necol 1999;94:364-70.

13. Leduc L, Wheeler JM, Kirshon B, Mitchell P, Cotton DB. Coagulation profile in severe preeclampsia. ObstetGynecol 1992;79:14-8.

14. Kramer RL, Izquierdo LA, Gilson GJ, Curet LB, Qualls R. "Preeclamptic labs" for evaluating hypertension in pregnancy. J ReprodMed 1997;42:223-8.

15. Osmanagaoglu MA, Topçuoglu K, Ozeren M, Bozkaya H. Coagulation inhibitors in preeclamptic pregnant women. Arch GynecolObstet 2005;271:227-30.

16. Fitzgerald MP, Floro C, Siegel J, Hernandez E. Laboratory Findings in hypertensive disorders of pregnancy. J Natl Med Assoc 1996;88:794-98.

17. Kobayashi T, Tokunaga N, Sugimura M, Kanayama N, Terao T. Predictive Values of Coagulation/Fibrinolysis Parameters for the Termination of Pregnancy Complicated by severe preeclampsia. SeminThrombHemosst 2001;27:137-41 